\title{
Intergénérécité et Histoire dans les textes d'Assia Djebar
}

\author{
Mohamed Boudjadja \\ Faculté des Lettres et des Langues, Université de Sétif $2^{*}$
}

Cette réflexion se propose d'analyser l'écriture croisée des textes d'Assia Djebar. En optant pour l'intergénéricité comme choix stylistique, l'auteure refuse le cloisonnement générique au profit de l'ouverture. Des discours pluriels et variés s'imbriquent et s'interpénètrent dans ses romans, mais encore, des événements historiques, des témoignages et de l'autobiographique se croisent et s'amalgament avec la fiction. Les ressources historiques sont insérées en alternance avec des séquences narratives diverses.

Assia Djebar donne également une nouvelle signification à l'Histoire en transgressant les frontières entre les genres classiques. Son écriture, libérée et novatrice, semble s'inscrire dans cette tendance contemporaine de mélange de genres, de tons, de formes : un trait indéniable du roman contemporain.

L'hétérogénéité qui se dégage de l'interconnexion entre le roman et les autres arts modifie-t-elle le sens de l'écriture et la posture lectorale ? Les effets d'écriture produits dans les textes de Djebar par le recours à l'Histoire et aux autres genres ne sont-ils pas un signe de renouvellement du roman francophone?

Mots-clés : écriture, Histoire, intergénéricité, roman moderne.

Objet aussi insaisissable qu'incontournable, le roman, un genre littéraire chargé d'enjeux multiples, a de tout temps été controversé. En Algérie, il a été introduit dans sa tradition occidentale après la conquête française. Aspirant à lui donner un cachet particulier parce qu'il n'est pas, a priori, une forme « locale », les écrivains algériens contemporains diversifient les formes de ce type de discours en se servant notamment de l'« intergénéricité » comme établissement de sens. Ils recourent à des stratégies d'écriture basée essentiellement sur la« tricherie » sur le genre. Roland Barthes dira : «cette tricherie salutaire, cette esquive, ce leurre magnifique, qui permet d'entendre la langue hors-pouvoir, dans la splendeur d'une révolution permanente du langage, je l'appelle pour ma part : littérature » (Barthes 1978 : 16).

\footnotetext{
*boudja192003@yahoo.fr
} 
Assia Djebar (1936-2015), qui est l'un de ces écrivains, s'est servi du roman pour raconter la mémoire collective en accordant également une place de choix à une écriture croisée, une écriture qui semble s'inscrire dans cette tendance contemporaine de mélange de genres, de tons, de formes, des arts...Les ressources historiques, les traces de la peinture, de la musique, sont exploitées dans ses romans qui regorgent à la fois de référents historiques et autobiographiques mais également d'insertions en alternance avec des séquences narratives diverses et se distinguent, en conséquence, par ce que François Harvey appelle l'« intergénéricité ». À ce propos, Jacques Chevrier observe que l'hybridité générique est la règle pour les œuvres postcoloniales « dans la mesure où les catégories habituelles (roman, poésie, théâtre...), héritées des modèles occidentaux, font de plus en plus l'objet d'une remise en question » (Chevrier 1989 : 223).

Alors, l'hétérogénéité qui se dégage de l'interconnexion entre le roman et les autres genres, voire les autres arts, modifie-t-elle le sens de l'écriture et la posture lectorale ? Aussi, les effets d'écriture produits dans les textes de Djebar par le recours à l'Histoire et aux autres genres ne sont-ils pas un signe de renouvellement du roman francophone?

Compte tenu de ces prémisses, notre analyse sera organisée selon trois axes : « À la croisée des genres », « La fictionnalisation de l'Histoire », « L'interconnexion des genres et ses effets $»$.

\section{1.À la croisée des genres}

Historiquement, c'est à partir des années quatre-vingt du siècle dernier que l'écriture d'Assia Djebar rompt avec la chronologie. S'inscrivant dans la modernité, elle emprunte à plusieurs genres, multiplie les discours, plonge dans différents temps et fait télescoper le passé et le présent.

Dans ses romans (de la seconde génération) où non seulement plusieurs voix se rencontrent, mais encore des discours pluriels et variés s'imbriquent, se chevauchent, s'interpénètrent, l'espace romanesque devient intergénérique. Tous les genres s'engloutissent. Les événements historiques, les témoignages et l'autobiographique s'amalgament avec la fiction.

Mêlant l'écriture autobiographique et l'approche historique, L'Amour, la fantasia se présente comme un espace romanesque hybride où se croisent plusieurs formes littéraires et dont la structure désempare le lecteur. Sa conception comme une superposition de strates temporelles forge son propre style romanesque polyphonique et hybride.

Ainsi, les lois du genre se trouvent défiées par la multiplication des narrateurs et la superposition des strates temporelles qui donnent au roman l'aspect d'un collage de plusieurs voix. «Tous ces genres qui entrent dans le roman, y intro- 
duisent leurs langages propres, stratifient donc son unité linguistique et approfondissent de façon nouvelle la diversité de ses langages » (Bakhtine 1987 : 134-135).

C'est dans ce sens que la narratrice de Loin de Médine transcrira les récits oraux des femmes. Elle s'appuie sur ce que la mémoire collective rapporte. Les contes se posent dans le récit comme un argument historiquement attesté.

La poésie est présente également dans les romans d'Assia Djebar. Abdallah, un personnage du roman Loin de Médine, au cours d'une séparation forcée, souffrit si vivement qu'il se mit à trouver des accents poétiques. C'est la douleur qui fait jaillir des profondeurs intimes un chant improvisé et très puissant.

C'est sur « un air de nay ${ }^{1}$ » que s'achève L'Amour, la fantasia (la troisième partie du roman plus particulièrement) où nous relevons la présence d'un poème, c'est le Sistre (Djebar 1985 : 156). Assia Djebar y exprime l'amour et le désir à travers un chant de force et où se dégage une forte charge musicale.

Recherchant le développement d'un nouvel effet de réel pour réaliser l'« écriture de creusement » qui constitue particulièrement son style, Assia Djebar accomplit un travail sur les formes génériques. Dans ses œuvres, la fiction et la réalité sont directement liées.

Mais les frontières entre le témoignage, le fictionnel et l'autobiographique restent floues, autrement dit le genre littéraire semble hybride pour s'écrire et réécrire l'Histoire.

\section{La fictionnalisation de l'Histoire}

Il est connu qu'Assia Djebar s'est intéressée à tous les genres de la littérature (romans, nouvelles, poèmes, autobiographie, théâtre), et bien au delà, le cinéma, la peinture, la musique. Mais la présence dans ses textes de l'Histoire est fort remarquable : son œuvre s'oriente de plus en plus vers le réel et devient une réflexion sur 1'Histoire.

En effet, fiction et Histoire sont constamment imbriquées l'une dans l'autre et l'Histoire de l'Algérie est la matière principale dans ses romans. Ceux-ci sont fortement référenciés si bien que l'insertion de l'histoire de la conquête du pays par la France, puis celle de la guerre de libération occupe un espace du discours littéraire constamment sollicité et sans cesse revisité par l'auteure.

Ce passé, bien souvent, se matérialise à travers l'écriture récurrente de la thématique de la guerre. L'auteure choisit, dans L'Amour, la fantasia, de raconter la prise d'Alger par les français à partir de 1830 où des événements historiques précis sont racontés dans la première partie, intitulée « La prise de la ville ou l'amour s'écrit », et d'autres sont relatés dans la deuxième partie « Les cris de la fantasia ", comme la razzia de deux tribus, en octobre 1840 ; l'enfumade d'une tribu encore insoumise, celle des Ouled Riah, le 18 juin 1845.

\footnotetext{
${ }^{1}$ Instrument musical arabe dit flûte de roseau.
} 
Assia Djebar n'omet pas, à chaque fois, de citer ses sources, le plus souvent constituées par des écrits de militaires français (lettres, rapports et journaux).Les témoignages oraux de femmes l'intéressent également. Elle renoue ainsi avec sa tradition et ses racines : la transmission du conte et du récit. Cette trace de l'oralité est la clé qui lui permet d'accéder à l'Histoire pour pouvoir ensuite réviser l'historiographie.

C'est aussi le cas de l'histoire de la guerre d'indépendance algérienne. Dans La Femme sans sépulture, l'auteure traite des volets de l'Histoire qui sont restés inachevés, et que la mémoire collective avait tendance à effacer. Elle y raconte le récit de Zoulikha, héroïne de la guerre d'indépendance algérienne, qui fut portée disparue après son arrestation par l'armée française. Cette femme extraordinaire était originaire de Césarée de Maurétanie (Cherchell dans l'Ouest algérien), ville natale d'Assia Djebar. Dans l'avertissement, l'auteure nous indique que ce récit respecte la « fidélité historique » et souligne également le rôle de l'imagination et de la fiction. « Dans ce roman, tous les faits et détails de la vie et de la mort de Zoulikha [...] sont rapportés avec un souci de fidélité historique [...] Toutefois, certains personnages [...] sont traités ici avec l'imagination et les variations que permet la fiction. J'ai usé à volonté de ma liberté romanesque » (Djebar 2002 : 9).

Ainsi, l'insertion de personnages réels, mis sur le même plan que les personnages fictifs, rattache le temps de la fiction au temps de l'histoire. La narratrice lutte contre l'oubli qui serait, d'une part la mise à mort totale du personnage, mais aussi la perte d'un composant important de la mémoire collective.

Le but d'Assia Djebar est de représenter la réalité en reconstruisant des périodes du passé et en s'appuyant sur des documents donnant un cadre attesté à son récit. Elle présente ainsi des histoires sous forme de références historiques qui deviennent à leur tour une forme de fiction. Elle se permet aussi d'introduire des commentaires ou des explications qui mettent l'histoire à la portée du lecteur.

Il est clair que, derrière la fiction, les romans renvoient immanquablement à des circonstances ou à des événements qui font partie de l'Histoire. L'organisation particulière de ses textes répond à une logique associative mettant en rapport des pans précis de l'Histoire de l'Algérie, à un espace, à un lieu et, dans une quête de fictionnalisation : l'histoire se transforme et un récit s'amorce.

Il reste que le travail d'Assia Djebar en tant que romancière et historienne, engagements qui semblent différents au premier abord, se révèlent relativement complémentaires. L'écrivaine rend compte ainsi du passé par sa mise en récit. Et si la fiction participe à l'élaboration du sens de l'Histoire, les romans d'Assia Djebar concourent à la constitution d'une certaine intelligibilité de l'Histoire. 


\section{L'interconnexion des genres et ses effets}

Considérant les genres littéraires comme des catégories abstraites permettant de rendre compte des liens de régularité qui unissent différentes œuvres entre elles, la rencontre du lecteur et du texte est alors inévitable. Dans la perspective herméneutique, P. Ricœur insiste sur la perception générique et qualifie les attentes du lecteur de déterminantes : « les paradigmes reçus structurent les attentes du lecteur et l'aident à reconnaître la règle formelle, le genre ou le type exemplifiés par l'histoire racontée. Ils fournissent les lignes directrices pour la rencontre entre le texte et son lecteur » (Ricœur 1983 :145).

L'écriture singulière d'Assia Djebar qui s'inscrit dans un champ littéraire national et international se caractérise, entre autres, par l'interconnexion générique. Ses œuvres se présentent comme de véritables ouvrages résultant d'un assemblage de divers éléments, révélateurs, certes, d'un souci créatif et esthétique.

Le lecteur qui est convié à des lectures plurielles ne semble pas indifférent à l'hétérogénéité des textes d'Assia Djebar, voire de l'hybridité générique. Il est perplexe devant toute classification générique puisqu'il n'arrive pas à préciser le genre de l'œuvre. C'est souvent l'effet de surprise, la curiosité scientifique et la soif de la recherche qui animeront ses interrogations.

Dans l'ouverture de Femmes d'Alger dans leur appartement, l'écrivaine mentionnait quelques éléments de la technique d'écriture de ses œuvres qui suivront : «Conversations fragmentées, remémorées, reconstituées...Récits fictifs, visages et murmures d'un imaginaire proche, d'un passé-présent se cabrant sous l'intrusion d'un nouveau informel » (Djebar 1980 : 7).

À partir de la déclaration d'intention de l'écrivaine elle-même, le lecteur de ses œuvres peut inscrire son Quatuor dans le genre autobiographie: «C'est un quatuor dans lequel je peux regarder mon enfance, mon adolescence, ma formation, jeter un coup d'œil sur ma vie, parce qu'avec l'âge évidemment, je peux la regarder comme si c'était celle d'une autre. Donc, je me suis essayée à cette tentation de l'autobiographie dans la maturité » (Djebar 1993 : 9-24).

Pourtant, il est également possible de repérer différents discours dans les volets de ce Quatuor. En plus des discours autobiographiques, on y trouve des discours historiques, mythiques, comme nous l'avons déjà indiqué.

De même, Vaste est la prison qui est présenté comme « roman » par l'éditeur est plutôt une œuvre éclatée où les cloisonnements sont tombés. La structure du texte ne semble pas répondre à la configuration du roman. La cohérence thématique est assurée par une combinaison de souvenirs qui participe à la construction d'une signification.

Cette œuvre, marquée par la superposition des souvenirs, s'avère être plus un montage de séquences et de scènes qui ont influencé la narratrice. Au seuil du 
texte, on trouve, un souvenir qui date de quinze ans : le moment où la narratrice accompagnait sa belle-mère au hammam : «A cette époque, il y a presque quinze ans de cela, je fréquentais, chaque samedi après-midi, un hammam qui se trouvait dans le cour ancien d'une petite ville algérienne, au pied de l'Atlas. [...] J'y allais avec ma belle-mère qui y rencontrait. » (Djebar 1995 : 2).

Ainsi, la narratrice brouille les pistes de lecture. Les deux indications génériques, roman et autobiographie, sont en contradiction et les frontières des deux genres sont dépassées.

Elle avoue cela :

Malgré mon effort de réminiscence, se brouille l'exact premier jour de la première rencontre, anodine ou importante, pour ces deux personnages que j'esquisse (il n'y a en moi nul désir de fiction, nulle poussée d'une arabesque inépuisable déployant un récit amoureux) - non, ne m'enserre que la peur paralysante ou l'effroi véritable de voir cette fracture de ma vie disparaître irrémédiablement. (Djebar 1995 : 49-50)

Cela est remarquable dans L'Amour, la fantasia qui est considéré comme une « autobiographie plurielle». (Déjeux 1994 : 116)

Au début du texte, l'histoire est personnelle puisqu'on lit : « Fille arabe allant pour la première fois à l'école, un matin d'automne, main dans la main de son père » (Djebar 1995 : 11), mais elle devient par la suite collective: « Ecrire ne tue pas la voix, mais la réveille, surtout pour ressusciter tant de sœurs disparues » (Djebar 1995 :285).

De plus, des chapitres historiques s'alternent avec des chapitres autobiographiques (les souvenirs d'enfance et de jeunesse de la narratrice). Le tout «formant chiasme entre elles » (Calle-Gruber $2001: 45$ ).

Dans sa quête formelle, Assia Djebar transgresse l'autobiographie en usant d'une écriture de dislocation, une écriture constamment en construction. Elle revendique une " liberté romanesque » qui lui permet de s'orienter dans ces espaces ambigus que sont ses œuvres - notamment celles dites autobiographiques. Ainsi conçue, l'œuvre d'Assia Djebar garantit la mouvance du sens et l'errance de l'écriture. L'ambiguité générique devient avant tout une question de forme.

\section{Conclusion}

En guise de conclusion, il apparaît que l'intergénéricité qui caractérise les textes d'Assia Djebar est le corollaire d'un choix stylistique. En exploitant la souplesse du genre romanesque, le mélange de genres, qui n'était jadis que la résultante de l'impossibilité des écrivains à se contenir dans des frontières canoniques, y trouve place, confirme la porosité des frontières génériques et renou- 
velle les codes du roman. Il s'agit plus d'un refus du cloisonnement générique au profit de l'ouverture qui compose à la lisière de la multigénéricité.

Aussi, en transgressant les canons esthétiques autobiographiques traditionnels, ses romans donnent une nouvelle signification à l'Histoire. L'auteure, par la fictionnalisation de l'Histoire, revisite, réécrit son histoire et celle de son pays et réalise un autre réel à la fois possible et plausible. C'est à travers les détours de l'histoire collective, ancienne et récente qu'elle arrive à son histoire singulière, propre au genre autobiographique.

Enfin, il nous est permis d'affirmer que les textes de Djebar ont révélé que le roman francophone contemporain se constitue essentiellement dans la singularité d'une poétique de l'hybridité transgénérique. C'est en cela que l'œuvre littéraire tient tout son sens chez Assia Djebar.

\section{Références bibliographiques}

Djebar 1980 : A. Djebar, Femmes d'Alger dans leur appartement, Paris : Editions des Femmes.

Djebar 1985 : A. Djebar, L’Amour, la fantasia, Paris : J. C. Lattès.

Djebar 1991 :A. Djebar, Loin de Médine, Paris : Albin Michel.

Djebar 1995 : A. Djebar, Vaste est la prison, Paris : Albin Michel.

Djebar 2002 : A. Djebar, La Femme sans sépulture, Paris : Albin Michel.

Djebar 1993 : A. Djebar, « Pourquoi j'écris », in E. Ruhe (dir.), Europas islamische Nach-

barn (Studien zur Literatur und Geschichte des Maghreb, Vol 1), n¹, Würzburg :

Königshausen und Neumann, 9-24.

Déjeux 1994 : J. Déjeux, La littérature féminine de langue française au Maghreb, Paris : Karthala.

Bakhtine 1987 : M. Bakhtine, Esthétique et théorie du Roman, Paris : Gallimard.

Barthes 1978 : R. Barthes, Leçon, Paris : Seuil.

Calle-Gruber 2001 : M. Calle-Gruber, Assia Djebar ou la résistance de l'écriture. Regards d'un écrivain algérien, Paris: Maisonneuve \& Larose.

Genette 1982 : G. Genette, Palimpseste, la littérature au second degré, Paris : Seuil.

Harvey 2011 : F. Harvey, Alain Robbe-Grillet :roman composite. Intergénéricité et intermédialité, Paris : L'Harmattan.

Ricoeur 1983 : P. Ricœur, Temps et récit I, Paris: Seuil. 


\section{Mohamed Budžadža}

\section{Međužanrovski pristup i Istorija u tekstovima Asje Đebar}

U članku se analizira ukršteno pismo u tekstovima Asje Đebar. Opredelivši se za međužanrovski pristup (intergeneričnost) kao stilističko polazište, spisateljica odbacuje žanrovsku razdvojenost. U njenim romanima preklapaju se i prožimaju višestruki i raznoliki diskursi, dok se istorijski događaji, svedočanstva i autobiografsko ukrštaju i spajaju sa fikcijom. Istorijski izvori uvedeni su naizmenično sa različitim narativnim sekvencama. Asja Đebar ujedno donosi novo značenje Istoriji time što prekoračuje granice klasičnih žanrova. Njeno pismo, oslobođeno i inovativno, izgleda da se priključuje savremenom trendu mešanja žanrova, tonova i formi, što predstavlja neporecivu odliku savremenog romana. Da li heterogeneričnost, koja nastaje u susretu romana i drugih umetnosti, menja smisao pisanja i čitalački stav? U članku se sugeriše da su postupci koje Asja Đebar u tom pogledu primenjuje u svojim tekstovima pokazatelj obnove frankofonog romana.

Ključne reči: pismo, Istorija, intergeneričnost, moderni roman 